\title{
Where are we Standing with Childhood Cancer in Middle- and Low-Income Countries?
}

\author{
Roberto Rivera-Luna*1, Alberto Olaya-Vargas ${ }^{2}$ and Armando Martínez-Avalos ${ }^{2}$ \\ ${ }^{1}$ Professor of Pediatric Oncology, UNAM, National Institute of Pediatrics, Mexico \\ ${ }^{2}$ Associate Professor of Pediatric Oncology, UNAM, National Institute of Pediatrics, Mexico
}

\section{EDITORIAL}

Childhood cancer worldwide constitutes an ever-growing health problem. It is estimated every year, between 175,000 and 250,000 children will be diagnosed with cancer throughout the world. However, these numbers may well be underestimations given the lack or substandard cancer registries especially in the middle- and low-income countries (MLIC). Nearly 80 to $90 \%$ of these cases are seen in MLIC, where overall survival is close to $50 \%$. Three fourths of global childhood cancer-related deaths happen in resource-limited countries [1].

Childhood cancer in the High income countries (HIC) have changed the outlook of this catastrophic disease in the last century, improving the survival rate to around $85 \%$ of the most common entities like acute lymphoblastic leukemia, lymphomas, germ cell tumors, Wilms tumor and some other [2]. In Mexico as in the rest of MLIC childhood cancer constitutes a financial, social and health burden, with 8,000 new cases diagnosed/per year [3]. This requires to be addressed and finance from the Federal Government, especially if we consider that the total population of Mexico is of 130 million inhabitants, with 55\% under the line of poverty. Every three minutes a child is diagnosed with cancer worldwide. The incidence in Mexico is 151 new cases/million/year [4], while globally it is $127.5 /$ million/year. In our country childhood cancer is consider the second cause of mortality between 4 to 15 years [5]. The mortality rate has been in the past 15 years of 4.6/100,000 per year.

There is more than $40 \%$ difference in overall survival in childhood cancer between HIC and MLIC, even amongst children in neighboring countries. This gap is secondary to the limited knowledge of childhood cancer among family physicians, in the general population, to almost absent public campaigns about childhood cancer, poorly equipped hospitals in more than $50 \%$ and currently to the economic burden and shortage of antineoplastic chemotherapy.

Mexico is a country with 2 million square kilometers that with the current pandemic of Covid19 can hardly handle this huge problem and children with cancer simultaneously, moreover we only have 328 board certified ped/hem/oncologists nationwide and under 70 certified hospitals for the care of this diseases.

Over the past 40 years Science has changed the outcome of childhood cancer in HIC. However, in MLIC this progress has not arrived due to obvious reasons. It is fundamental that this later nations should continue working at their possibilities and making changes in the sanitary area in order to improve the health care of all this children through several aspects that will include a national childhood cancer registry, certify medical institutions for childhood cancer, pediatric oncologists and paramedical personnel with continuous medical education programs, universities that promote pediatricians to enrolled into pediatric hem/oncology formal training. Other aspects that are basic is the education of the general population about childhood cancer and the importance to have an early diagnosis and proper treatment in a certified institution.

We have emphasized that in MLIC challenges to execute such strategies include a paucity of implementation research, formal policy evaluation, and costing data. The ideal structure of such strategies in these countries is currently unknown, given severe resource constraints, deficits in infrastructure, and competing health needs [6].

In summary as we have published earlier the pediatric malignancies account for a growing proportion of overall global
Quick Response Code:

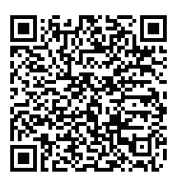

Address for correspondence: Roberto Rivera-Luna, Head of the Division of Pediatric Hem/Oncology, National Institute of Pediatrics, Mexico

Received: November 23, $2020 \quad$ Published: December 02, 2020

How to cite this article: Roberto RL, Alberto OV, Armando MA. Where are we Standing with Childhood Cancer in Middle- and Low-Income Countries?. 2020 - 2(6) OAJBS.ID.000237. DOI: 10.38125/OAJBS.000237 
childhood mortality, justifying renewed efforts to improve cure rates for this population in MLIC. The creation of government sponsor programs for childhood cancer is probably the best approach for these diseases. While the financial coverage of pediatric oncology care should be an integral part of any such strategy, maximal impact will require additional policies addressing the structural aspects of care delivery and the creation of childhood cancer registries.

\section{REFERENCES}

1. (2014) PAHO. Early diagnosis of childhood cancer. Washington, USA.

2. Phillips SM, Padgett LS, Leisenring WM, Stratton KK, Bishop K, et al (2015) Survivors of childhood cancer in the United States: prevalence and burden of morbidity. Cancer Epidemiol, Biomarkers \& Prev 24: 653663.
3. Rivera-Luna R, Zapata-Tarres M, Shalkow-Klincovstein J, VelascoHidalgo L, Olaya-Vargas A, et. al. (2017) The burden of childhood cancer in Mexico: Implications for low- and middle-income countries. Pediatr Blood \& Cancer 64(6).

4. Rivera-Luna R, Velasco-Hidalgo L, Zapata-Tarrés M, Cárdenas-Cardos R, Aguilar-Ortiz MR (2017) Current outlook of childhood cancer epidemiology in a middle-income country under a public health insurance program. Pediatr Hematol Oncol 34(1): 43-50.

5. Rivera-Luna R, Shalkow-Klincovstein J, Velasco-Hidalgo L, CárdenasCardós R, Zapata-Tarrés M, et.al. (2014) Descriptive epidemiology in Mexican children with cancer under an open national public health insurance program. BMC Cancer 14: 790.

6. Gupta S, Rivera-Luna R, Ribeiro RC, Howard SC (2014) Pediatric oncology as the next global child health priority: the need for national childhood cancer strategies in low- and middle-income countries. PLOS Med 11(6): e1001656. 